Hydroécol. Appl. (1997) Tome 9 Vol. 1-2, pp. 169-193

\title{
Distribution spatio-temporelle du phytoplancton dans le réservoir de Petit-Saut (Guyane Française)
}

\author{
Seasonal and spatial distribution of phytoplankton \\ in Petit-Saut reservoir (French Guiana)
}

\section{A. Vaquer, V. Pons et J. Lautier}

Laboratoire d'Hydrobiologie Marine et Continentale, UMR CNRS 5556 - Université de Montpellier II, place E.-Bataillon, F-34090 Montpellier cedex 5.

Résumé. - La retenue de Petit-Saut a été colonisée dès 1994 par le phytoplancton, composé de Chlorophycées banales, adaptées aux conditions environnementales difficiles. La biodiversité augmente actuellement avec des Desmidiées typiques des eaux tropicales acides. Le picophytoplancton $(<2-3 \mu \mathrm{m})$ domine le phytoplancton $(60 \%$ des cellules) depuis la mise en eau, jusqu'à l'amont du lac. II constitue un élément déterminant de la période de colonisation. Les biomasses chlorophylliennes $\left(0,8\right.$ à $\left.80 \mu \mathrm{gl}^{-1}\right)$ sont maximales entre 0 et $10 \mathrm{~m}$ et en période sèche. Elles sont très faibles en zone amont du lac sous l'influence du Sinnamary $\left(<0,2 \mu \mathrm{gl}^{l^{-1}}\right)$, puis augmentent dans le système lacustre et sont plus ou moins régulées jusqu'au barrage sous l'effet des facteurs environnementaux (lumière, broutage). Dans le Sinnamary aval, les concentrations pigmentaires faibles sont significativement corrélées à la concentration moyenne des pigments dans la colonne d'eau juste à l'amont du barrage. La productivité du phytoplancton est limitée dans la couche photique oxygénée (0-5 m). La lumière transmise très atténuée en zone amont $\left(\mathrm{K} \pm 2,5 \mathrm{~m}^{-1}\right)$ par la MES fluviale augmente dans le temps dans la zone lacustre $\left(\mathrm{K} \pm 0,95 \mathrm{~m}^{-1}\right)$. Elle représente le premier facteur limitant du phytoplancton, en admettant l'existence d'un flux important des nutriments à partir de la couche anoxique. Inversement les bactéries photosynthétiques abondantes (200 à $300 \mathrm{\mu gl}^{-1}$ de bactériochlorophylle) à la limite inférieure de la couche photique peuvent être très compétitives vis à vis de ces nutriments. L'abondance phytoplanctonique est à la base du développement de la microfaune planctonique, avec un effet de rétroaction important.

Mots Clés. - Phytoplancton, chlorophylle, évolution spatio-temporelle, picophytoplancton, production. 
Abstract. - Phytoplankton have colonized the reservoir of Petit-Saut since the filling phase (1994). The algal assemblage is composed of common Chlorophyta, which are well adapted to extreme environmental conditions. At the present time, the increase in the number of Desmid species characteristic of tropical ecosystems is contributing to greater algal biodiversity. Picophytoplankton $(<2-3 \mu \mathrm{m})$ is the dominant group in the phytoplanktonic community throughout the lake $( \pm 60 \%$ of total cells) playing a predominant role during the colonization period. Chlorophyll biomasses $\left(0.8\right.$ to $\left.80 \mu^{\mathrm{g}^{-1}}\right)$ are maximum between 0 and 10 meters in depth and during dry periods. They are very low in the upstream part of the lake, influenced by the Sinnamary $\left(<0.2 \mu \mathrm{g} \mathrm{I}^{-1}\right)$, increase in the lacustrine system and are more or less controlled down to the dam by several environmental factors (light, grazing). In the Sinnamary downstream, low pigment concentrations are significantly correlated with the average concentration of pigments in the water column upstream the dam. Phytoplankton productivity is limited in the photic layer and oxygenated $0.5 \mathrm{~m}$ upper layer. Available light is strongly attenuated in the upstream riverine zone $\left(\mathrm{K}+2.5 \mathrm{~m}^{-1}\right)$ by suspended matter, but increases in the lacustrine zone $\left(\mathrm{K} \pm 0.95 \mathrm{~m}^{-1}\right)$. It is the main factor limiting phytoplankton growth, given significant nutrient inputs beginning in the anoxic layer. Conversely, the abundant photosynthetic bacteria (200-300 $\mathrm{g} \mathrm{I} \mathrm{I}^{-1}$ of bacteriochlorophyll) at the lower limit of the photic layer are potential competitors for nutrients. The abundant phytoplankton contribute to the microfauna development with an important feedback effect.

Key words. - Phytoplankton, chlorophyll, spatio-temporal distribution, picophytoplankton, production.

\section{INTRODUCTION}

Le phytoplancton est un élément déterminant du fonctionnement d'un écosystème aquatique. II est à l'origine de la matière organique nouvelle élaborée à partir des éléments minéraux du milieu, contribuant à la mise en place des chaînes trophiques.

La retenue de Petit-Saut est un réservoir nouvellement créé en zone forestière tropicale, destiné à la production hydroélectrique. Cette situation est une opportunité très intéressante pour l'étude de la mise en place de différents processus chimiques et biologiques du fonctionnement d'un lac, comme ceux décrits par Kimmel et al. (1986). Dans le cas du phytoplancton, elle permet notam- ment l'étude de la colonisation et de l'installation d'un peuplement algal à partir d'un fleuve en milieu forestier fermé peu favorable au développement de phytoplancton. Par ailleurs, s'agissant de la Guyane Française, la flore phytoplanctonique est peu connue. Les études ponctuelles de Thérézien (1985), de Bourelly et al. (1982) et Guerlesquin et al. (1991) ont concerné essentiellement la zone côtière (marais, criques,...). Les données concernant les fleuves et criques forestières sont très limitées.

D'un point de vue plus appliqué, le phytoplancton a un rôle majeur dans le contrôle de la qualité de l'eau en amont du barrage conditionnant la qualité de celle restituée en aval. La photosynthèse du phytoplancton est une des sources principales de l'oxy- 
génation de l'eau dont les taux seront très fortement altérés par la dégradation de l'énorme quantité de biomasse végétale laissée en place lors de la mise en eau de la retenue. Mais la production du phytoplancton est en même temps une source de nouvelle matière organique qui, entrant dans la boucle microbienne, est consommatrice d'oxygène. Par ailleurs le phytoplancton est un maillon primordial des réseaux trophiques permettant notamment le développement de la microfaune planctonique puis des poissons lacustres. Ces derniers pourraient constituer une ressource économique non négligeable.

L'objectif de cet article est de présenter les résultats d'une étude concernant l'installation d'un peuplement phytoplanctonique, en termes de composition, structure et biomasse pendant les trois premières années suivant le mise en eau de la retenue (1994-1996). L'intégration de cette étude dans un suivi écologique, pendant cette même période, des conditions environnementales physiques, chimiques et biologiques permet de donner les premiers éléments d'interprétation $\mathrm{du}$ fonctionnement $\mathrm{du}$ compartiment phytoplanctonique dans la retenue.

\section{MATÉRIEL ET MÉTHODES}

L'étude commencée lors de la mise en eau du barrage (janvier 1994) est basée sur un suivi temporel à différentes stations, incluant les stations étudiées par le Laboratoire Environne- ment de Petit-Saut, à une fréquence minimale mensuelle.

La station située juste en amont du barrage (BPS 1) est échantillonnée régulièrement sur toute la profondeur, en 11 niveaux : surface $-1 m,-2 m$, $-3 m,-4 m,-5 m,-7,5 m,-10 m$, $-15 m,-20 m,-30 m$, auxquels ont été ajoutés des niveaux intermédiaires dans la couche $0-10 \mathrm{~m}$ pour cerner au mieux la zone des maximums de biomasse.

La distribution spatiale du phytoplancton a été suivie le long d'un transect longitudinal comportant 15 stations (fig. 1), de l'amont vers l'aval : Takari-Tanté (1), Mouche (2), Aïmara (3), L'Autel (4), Bois-Blanc (5), Nassibo (6), Patawa (7), Bérard (8), Vata (9), Deux-Branches (10), Genipa (11), Tigre (12), Bagatelle (13), BPS3 (zone Champeau) (14), BPS (BPS1) (15). Ces stations ont été échantillonnées à environ $30 \mathrm{~cm}$ de profondeur et pour certaines campagnes entre $3 \mathrm{~m}$ et $8 \mathrm{~m}$ de profondeur suivant la profondeur des zones photiques et oxygénées. Plusieurs stations ont été également échantillonnées en surface à l'aval du barrage dans le fleuve Sinnamary: Seuil, à l'aval immédiat du barrage, Kerenroch, Venus, Combi et Sinnamary.

La composition des peuplements phytoplanctoniques est basée sur l'observation microscopique d'échantillons fixés (formaldehyde, $3-4 \%$ en concentration finale), permettant l'identification des principaux taxons.

Les dénombrements de la flore totale donnant le niveau d'abondance 


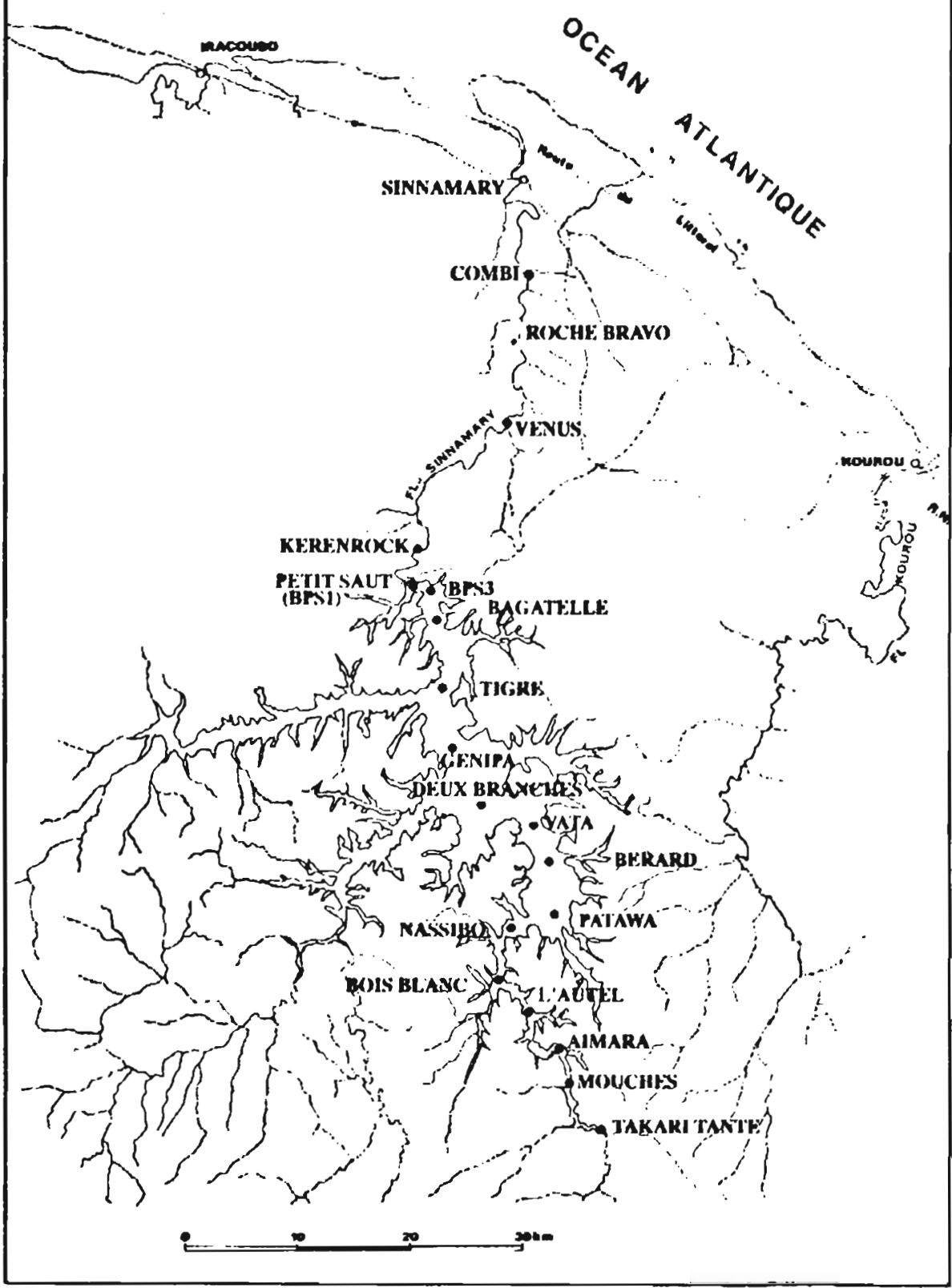

Fig. 1. - Le réservoir hydroélectrique de Petit-Saut sur le fleuve Sinnamary. Localisation des stations de prèlevement. (D'apres document EDF).

Fig. 1. - Petit-Saut Reservoir on the river Sinnamary. Location of sampling stations. (From EDF document). 
numérique ont été effectués par cytométrie en flux (CMF). Des échantillons de $1 \mathrm{ml}$ sont fixés (formaldéhyde, $0,5 \%$ en concentration finale) et conservés dans l'azote liquide suivant Troussellier et al. (1995). Des souséchantillons de 0,1 à $0,5 \mathrm{ml}$ sont analysés avec un cytometre en flux ACR-1000 (Brucker Spectrospin, France), en utilisant les fluorescences naturelles des cellules phytoplanctoniques, rouge pour la chlorophylle a, et verte pour les phycobiliprotéines. Les fluorescences sont obtenues par excitation des pigments à 470$490 \mathrm{~nm}$. Les fluorescences verte et rouge sont séparées à l'aide d'un filtre dichroïque large bande à $640 \mathrm{~nm}$ et récupérés respectivement à l'aide de filtres à $580 \pm 20 \mathrm{~nm}$ et $680 \pm 20 \mathrm{~nm}$ (Troussellier et al., 1993). Les dimensions et les fluorescences relatives des cellules sont rapportées à des billes fluorescentes de $2 \mu \mathrm{m}$ de diamètre. La disposition relative des cellules par rapport aux billes sur les cytogrammes a été précisée par des filtrations sur des membranes Nuclepore de $2 \mu \mathrm{m}$ de porosité.

Les biomasses phytoplanctoniques ont été estimées par la mesure des concentrations en chlorophylle a (Chla), effectuée suivant la méthode spectrofluorimétrique de Neveux et al. (1993), modifiée pour tenir compte des particularités du milieu. Des échantillons de 20-50 $\mathrm{ml}$ sont filtrés sur membrane en fibre de verre Whatman GF/F (porosité de $0,7 \mu \mathrm{m}$ ), conservés au congélateur, puis dans l'azote liquide. Les pigments sont extraits en 24 heures au froid avec de l'acétone à $90 \%$, après broyage du filtre.

Les pigments chlorophylliens constituent un indice habituellement utilisé de la biomasse phytoplanctonique. Dans le lac de Petit-Saut, les proportions des chlorophylles $a, b$ et $c$ ainsi que de leurs formes dégradées ont montré des anomalies importantes dès la mise en eau: des quantités de chlorophylle $b$ très largement supérieures à celles de la chlorophylle a, mais surtout des quantités de chlorophylle $c$ et de sa forme de dégradation alors que les phytoplanctontes connus pour contenir ces deux derniers pigments sont quasiment absents à l'observation microscopique. Ces anomalies ont été confirmées par l'examen des spectres de fluorescence qui montrent un glissement très net du maximum d'émission de la chlorophylle a $(671 \mathrm{~nm})$ d'environ $10 \mathrm{~nm}$ à $660 \mathrm{~nm}$. Les valeurs d'absorption ou de fluorescence des pigments d'origine végétale interfèrent donc avec celles d'autres pigments, comme cela a pu être détecté de façon identique dans d'autres milieux (Lechuga-Deveze, 1994). La séparation de ces pigments par chromatographie et HPLC a permis de montrer que ces pigments non végétaux s'apparentent du point de vue de leurs caractéristiques d'absorption et de fluorescence à une bactériochlorophylle proche de celle des bactéries vertes du genre Chlorobium. Toutefois les organismes contenant ce pigment n'ont pas encore pu être isolés, cultivés et identifiés. L'existence de bactéries photosynthétiques n'est donc pas montrée 
de façon formelle, mais elle constitue une hypothèse très vraisemblable.

La méthode de dosage des pigments chlorophylliens mise au point par Neveux et al. (1993) a donc été adaptée, avec l'aide de J. Neveux (Laboratoire Arago, Paris $\mathrm{VI}$ ), pour tenir compte de l'interférence de ce pigment sur le dosage de la chlorophylle a. Des tests analytiques effectués avec des solutions de chlorophylle a (Sigma) ont permis de vérifier que cette dernière était bien évaluée, même en présence de fortes quantités de bactériochlorophylle (Bchl). Inversement les interférences avec les chlorophylles $b$ et $c$ et les phéopigments végétaux ne sont pas entièrement écartées. La bactériochlorophylle a été estimée en prenant comme valeur d'absorption spécifique du bactériopigment celle de la chlorophylle a. II ne s'agit donc que d'une approximation, cependant vraisemblablement proche de la réalité au regard de la coloration verte très marquée des filtres et des extraits acétoniques rapportée au faible volume d'eau filtrée $(20-50 \mathrm{ml})$. On peut considérer que les concentrations de bactériochlorophylle sont exprimées en équivalent $\left(\mu \mathrm{gl}^{-1}\right)$ de chlorophylle $a$.

L'activité du phytoplancton a été estimée par la méthode de l'oxygène produit lors de la photosynthèse au cours d'incubation dans des flacons clairs et opaques à la lumière, in situ à 5 à 8 niveaux dans la couche photique. Les mesures sont effectuées à l'aide d'un oxymètre WTW OXY 196. Des essais de mesures d'incorporation de carbone ont été effectués suivant la méthode de Steeman Nielsen
(1952) modifiée par Riemann et al. (1991).

Les coefficients d'atténuation de la lumière dans l'eau ont été calculés à partir des mesures de l'intensité de l'énergie lumineuse transmise à l'aide d'un quantamètre LI COR 189 et d'une sonde Quantum LI-192S, dans la gamme des longueurs d'onde photosynthétiquement actives (400$700 \mathrm{~nm})$.

\section{RÉSULTATS}

\subsection{Le peuplement phytoplancto- nique : composition et abondance}

II existe peu d'informations concernant la flore phytoplanctonique des milieux aquatiques guyanais, et plus particulièrement des rivières. Bourrelly et al. (1982) ont donné une liste floristique sur des petits plans d'eau côtiers à proximité de Cayenne et d'Iracoubo, de même que Guerlesquin et al. (1991). Thérézien (1985) a prospecté ou analysé des prélèvements provenant d'un certain nombre de criques cotières et forestieres, et du fleuve Maroni. Dans son étude excluant les Diatomées, il décrit 557 espèces d'algues, dont 102 ont été trouvées dans des criques côtières, mais seulement 24 et 19 espèces seulement trouvées respectivement dans des petites criques forestieres et dans le Maroni. Bien que cette dernière étude ne soit pas exhaustive, loin s'en faut, elle montre la pauvreté floristique des eaux courantes guyanaises. Le fleuve Sinnamary ne fait pas exception: tres peu d'espèces 
ont été observées, notamment au cours de cette étude, et les espèces dominantes sont des Diatomées. Dans la plupart des cas les algues observées sont probablement des organismes de dérive, détachés de différents supports, troncs immergés et rochers des sauts amont. Harripersad et al. (1989) indiquent que les Diatomées dominent généralement la flore des criques et rivières du Surinam et que quelques Chlorophycées, dont des Desmidiées, y sont également présentes. Les espèces citées par ces derniers auteurs sont présentes dans la retenue de Petit-Saut, ce qui indiquerait que leur développement peut se faire à partir des apports par le fleuve ou les criques affluentes où elles sont passées inaperçues du fait de leur rareté. Cette faible abondance des organismes constitue un ensemencement extrêmement réduit amenant à un développement très lent, correspondant, par exemple, aux temps de latence très longs observés dans les cultures faites au laboratoire avec des inoculums trop dilués dans un grand volume de culture.

La plupart des espèces observées dans la retenue de Petit-Saut depuis 1994 ont été décrites dans les quelques études antérieures citées. Jusqu'à aujourd'hui, la flore est essentiellement composée d'espèces cosmopolites et le plus souvent ubiquistes. Quelques grandes espèces du microphytoplancton (> $20 \mu \mathrm{m}$ ), souvent coloniales, Eudorina elegans, Dinobryon sertularia, Dictyosphaerium pulchellum et Botryococcus braunii, se sont développées dès la mise en eau et sont encore bien représentées. Elles sont accompagnées par Peridinium cinctum, parfois abondant, de Phacus platalea. Une seule grande Desmidiée, Pleurotaenium sp., a été observée occasionellement. Quelques Cyanophycées filamenteuses (Oscillatoria) sont également présentes, mais généralement peu abondantes.

Le nanophytoplancton (2 à $20 \mu \mathrm{m}$ ) est surtout composé de Chlorophycées (Ankistrodesmus, Crucigeniella, Oocystis, Scenedesmus, Kirchneriella) et de quelques Desmidiées (Actinotaenium, Cosmarium, Staurastrum). II comprend également des Euglénophycées, Phacus et Trachelomonas (formes volvocina, hispida et armata), et de Chrysophycées du genre Mallomonas. Le nombre de Desmidiées, algues typiques des milieux acides tropicaux, a tendance à augmenter notamment depuis la fin de 1995. La quasi-absence des Diatomées durant cette période est une des caractéristiques remarquables de cette flore, qui est essentiellement dominée par des Chlorophycées et des Euglénophycées. Cette dominance a également été observée dans le réservoir de Samuel (Rondonia, Brésil) au cours de sa phase de mise en eau par Matsumura-Tundisi et al. (1989).

Les abondances numériques du phytoplancton obtenues par CMF varient très largement entre $10^{7}$ et 1,8 $10^{8}$ organismes par litre dans la couche photique et dans la zone lacustre du réservoir. Dans les trois dernières stations de la zone amont du lac, les abondances sont en revanche 
très faibles, de l'ordre de $10^{5}$ cellules par litre, voire inférieures à TakariTanté, station la plus en amont, ce qui confirme la pauvreté en phytoplancton du fleuve Sinnamary.

Une autre caractéristique remarquable de ce phytoplancton est la forte proportion des cellules dont la taille relative (par rapport à des billes de $2 \mu \mathrm{m}$ ) est proche ou inférieure à 2-3 $\mu \mathrm{m}$. En effet ces organismes représentent en moyenne $60 \%$ de l'abondance cellulaire totale (entre 37 et $77 \%$ ). Ils constituent le picophytoplancton, non discernable à l'observation directe et par suite non identifiable. L'analyse des cytogrammes montre que la quasi totalité des cellules ne présentent qu'une fluorescence rouge (chlorophylle a). La fluorescence verte ne concerne que quelques individus (moins de $1 \%$ ), indiquant la présence de rares Cryptophycées et Cyanophycées. Le picophytoplancton majoritaire n'est donc pas constitué de Cyanophycées (ou Cyanobactéries) comme cela est le cas dans de nombreux milieux (Jensen et al., 1994; McMurter et al., 1994), mais de petits eucaryotes indéterminés jusqu'à présent. Ces organismes sont très abondants et dominants depuis la mise en eau de la retenue de Petit-Saut. Enfin il ne semble pas exister, en première approximation, une répartition des espèces en fonction de la profondeur. Les mêmes especces se retrouvent dans toute la colonne d'eau. Par ailleurs certaines cellules restent viables après avoir subi les conditions d'anoxie dans la couche profonde du lac.
Elles sont susceptibles de se développer lorsqu'elles sont remises dans un milieu oxygéné et à la lumière.

\subsection{Les biomasses pigmentaires}

Les concentrations de chlorophylle $a$ sont comprises entre 0,05 et $80 \mu^{\prime-1}$. Elles sont maximales dans la couche 0-10 $\mathrm{m}$, et dans les stations aval de la retenue par rapport aux stations les plus amont. La chlorophylle $b$, mesurée hors influence de la bactériochlorophylle, est la chlorophylle accessoire dominante, tandis que la chlorophylle $c$ est très peu représentée. Le rapport $\mathrm{chl} b / \mathrm{chl}$ a moyen est de 0,17 , (entre 0,05 et 0,5 ), alors que le rapport chl c / chl a est 10 fois plus faible $(0,017$ en moyenne, entre 0,003 et 0,13 ). Quelques valeurs de ce rapport, supérieures à 0,05 , ont toutes été trouvées dans les 4 stations les plus amont de la retenue. La dominance des chlorophylle $a$ et $b$ est liée à la composition du peuplement phytoplanctonique: algues vertes (Chlorophycées) et Euglénophycées. Les groupes d'algues contenant de la chlorophylle $c$ (Cryptophycées, Dinophycées, Chrysophycées et surtout Bacillariophycées) sont très peu représentés et abondants dans la flore planctonique lacustre. L'augmentation relative des teneurs en chlorophylle $c$ dans la partie amont de la retenue confirme l'apport des Diatomées par les eaux fluviales. La phéophytine a (chlorophylle a dégradée) représente en moyenne $21,5 \%$ de la somme chlorophylle $a+$ phéophytine $a-$ entre 0,3 et $41 \%$. Elle augmente très 
sensiblement dans les zones profondes, en dessous de $15 \mathrm{~m}$ où elle atteint $56 \%$ en moyenne (entre 20 et $80 \%$ ). Elle montre clairement la dégradation du phytoplancton dans les zones profondes, anoxiques et aphotiques.

La relation entre les concentrations de chlorophylle a et l'abondance cellulaire est relativement satisfaisante, mais elle a tendance à se dégrader lorsque la fraction de picophytoplanctontes augmente en même temps que le nombre total des cellules, comme par exemple entre Vata et Nassibo (fig. 2).

La bactériochlorophylle est présente dès la mise en eau et son maximum se situe toujours en dessous de la chlorophylle $a$, entre 2 et $10 \mathrm{~m}$ de profondeur. Ses concentrations (en $\mu \mathrm{gl}^{-1}$ équivalent - chlorophylle a) sont généralement 2 à 10 fois plus élevées, atteignant souvent des valeurs comprises entre 200 et $300 \mu \mathrm{gl}^{-1}$. Au delà de $10 \mathrm{~m}$ de profondeur, elles diminuent à moins de $10 \mu \mathrm{gl}^{-1}$. La bactériochlorophylle est également présente jusqu'en surface, en mélange avec la chlorophylle $a$, à une concentration moyenne de $18,8 \mu \mathrm{gl}^{-1}$.

\section{3 Évolution temporelle des pig- ments dans la colonne d'eau}

L'examen des profils verticaux des pigments à la station BPS1 (fig. 3 et 4) met clairement en évidence la lo-

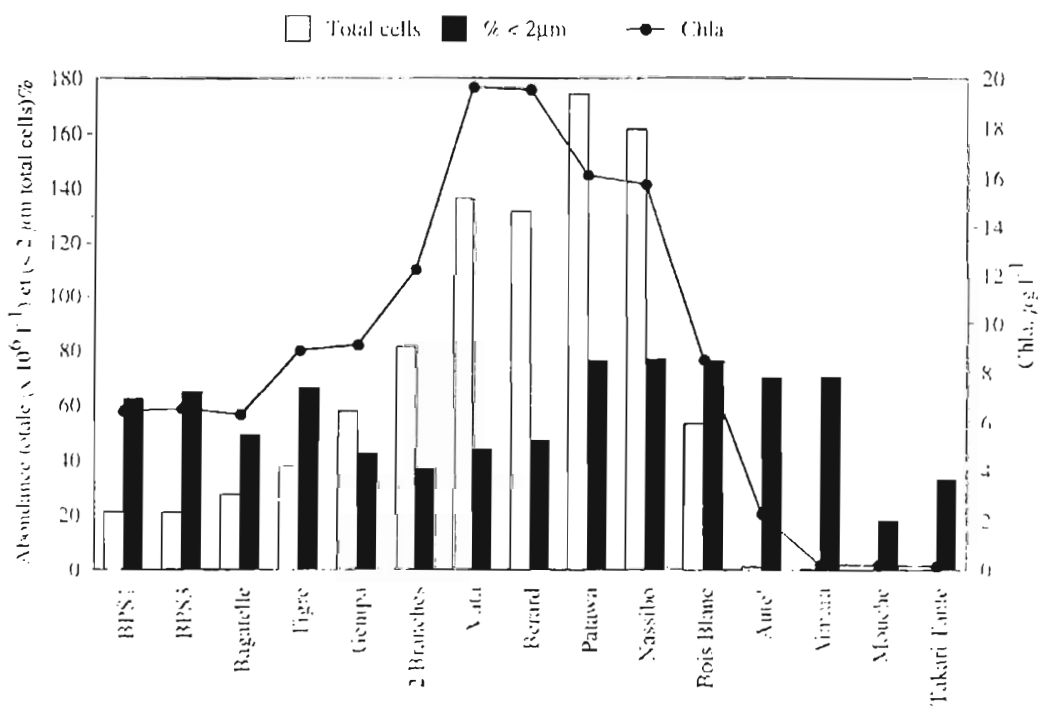

Fig. 2. - Variations des concentrations en chlorophylle a el de labondance celullaire totale entre Takari-Tanté et BPS1 en novembre 1996 en relation avec la proportion du picophytoplancton.

Fig. 2. - Covariations of chlorophyll a concentrations, total cells and picophytoplankton percentages from Takari-Tanté to BPS1 in November 1996. 


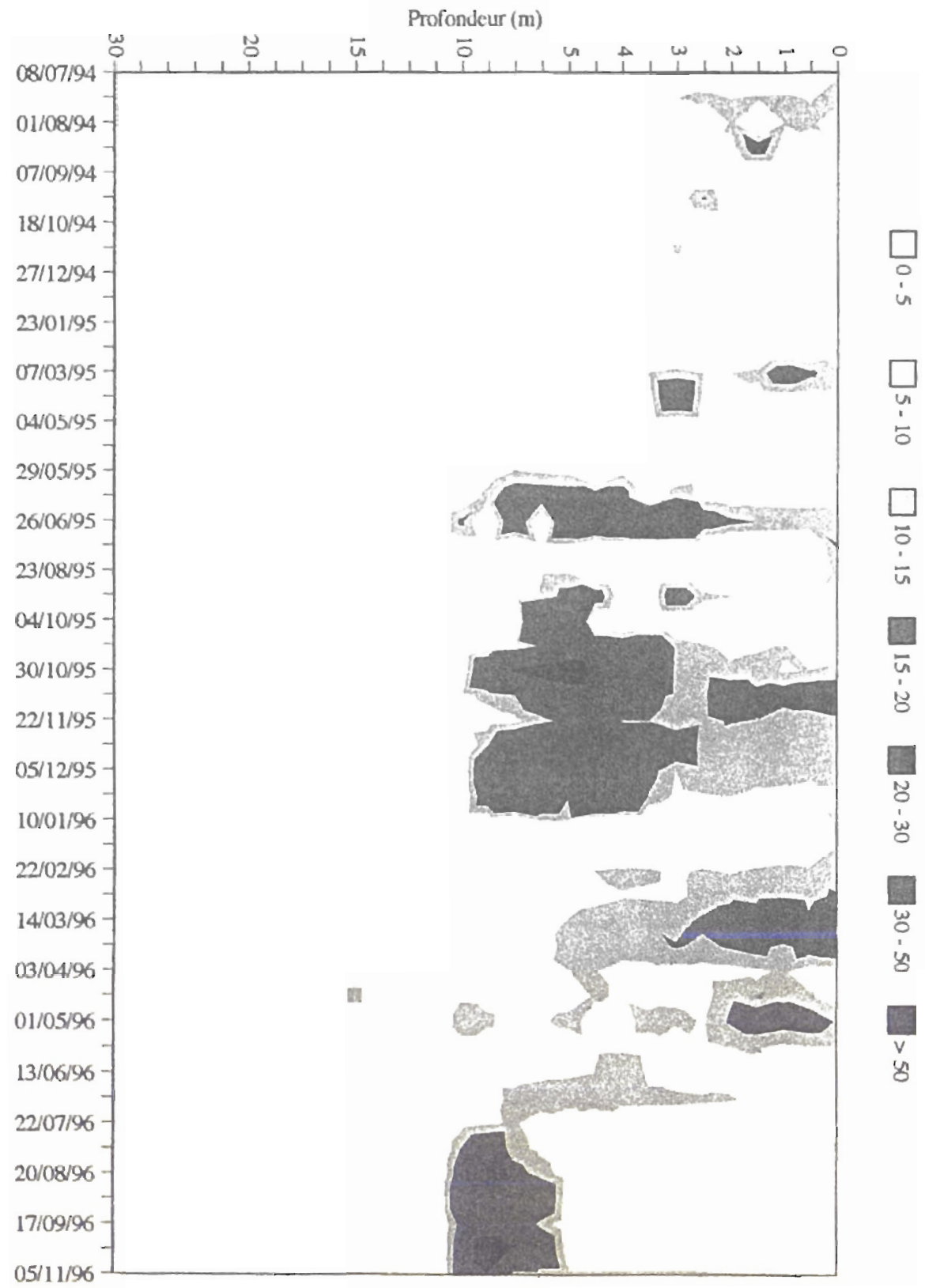

Fig. 3. - Evolution des concentrations de chlorophylle a $\left(\mu \mathrm{g} \mathrm{l}^{-1}\right)$ dans la colonne d'eau jusqu'à $30 \mathrm{~m}$ de profondeur à la station BPS1, située juste en amont du barrage, entre 1994 et 1996. (L'échelle des profondeurs est arbitraire pour faciliter la présentation).

Fig. 3. - Evolution of chlorophyll a concentrations $\left(\mu \mathrm{g} \mathrm{I}^{-1}\right)$ in the water column down to $30 \mathrm{~m}$ depth at station BPS1 during the '94-96 period. (Arbitrary depth scale for useful viewing). 


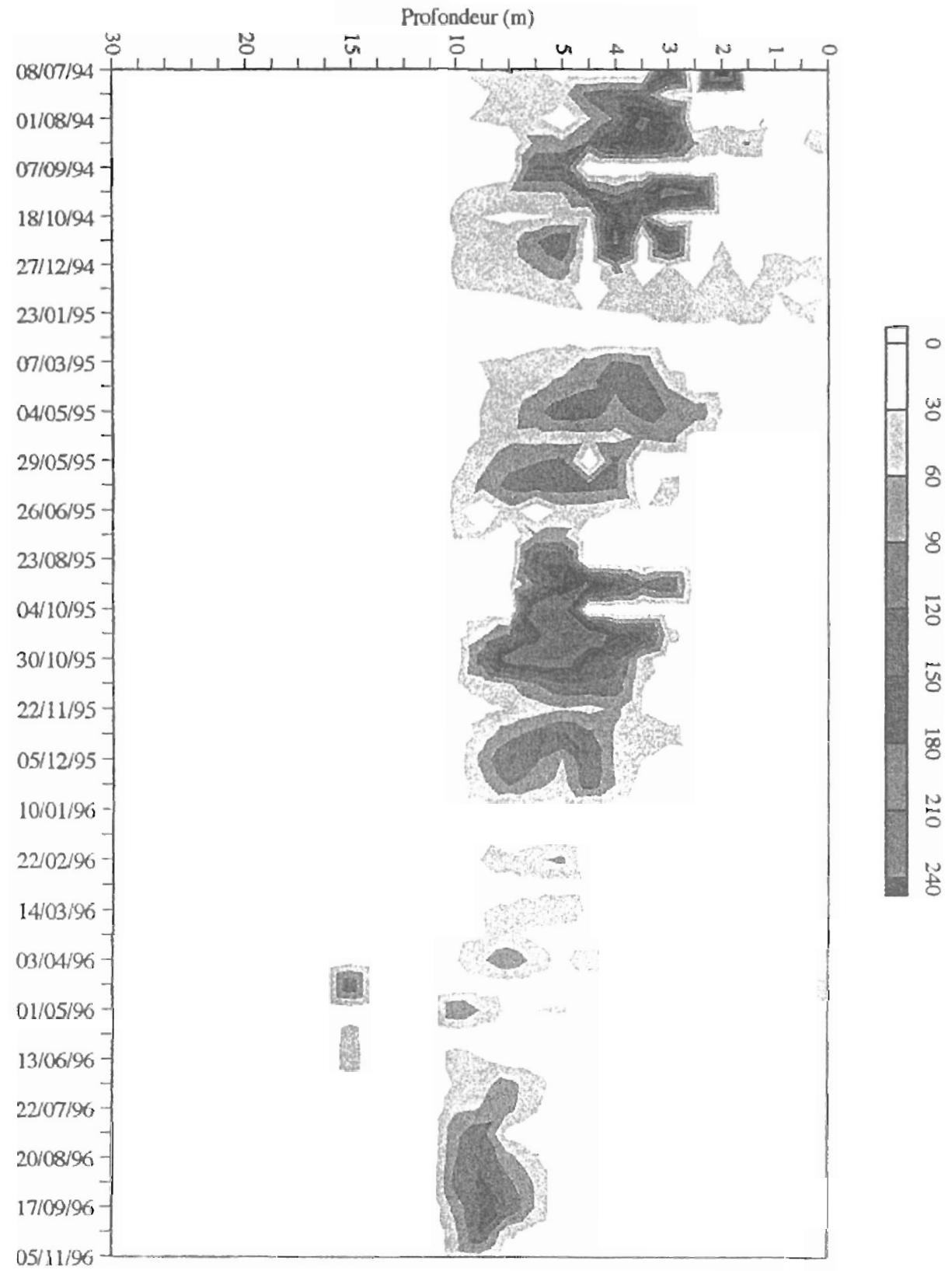

Fig. 4. - Evolution des concentrations de bactériochlorophylle $\left(\mu \mathrm{g}^{\mid{ }^{1}}\right)$ dans la colonne d'eau jusqu'à $30 \mathrm{~m}$ de profondeur à la station BPS1 entre 1994 et 1996. (L'échelle des profondeurs est arbitraire pour faciliter la présentation).

Fig. 4. - Evolution of bacteriochlorophyll concentrations $\left(\mu \mathrm{gl}^{-1}\right)$ in the water column down to $30 \mathrm{~m}$ depth at station BPS1 during the '94-96 period. (Arbitrary depth scale for useful viewing). 
calisation de la chlorophylle $a$ et de la bactériochlorophylle dans la couche 0-10 m de la colonne d'eau. La chlorophylle a présente jusqu'à la surface montre souvent un maximum plus profond, parfois dans la partie inférieure de la zone photique. La bactériochlorophylle également détectée en: surface est plus concentrée à la limite de la couche photique, voire immédiatement en dessous.

Les deux pigments évoluent en parallèle et montrent une périodicité saisonnière nette. Ainsi les développements maximum se produisent pendant la période sèche (août-novembre). Des développements moins marqués sont également observables pendant la petite saison sèche (marsavril). Pendant les saisons humides les concentrations pigmentaires sont généralement moins élevées et apparemment réparties de façon plus homogène dans la colonne d'eau. En dessous de $10 \mathrm{~m}$ et surtout de $15 \mathrm{~m}$ les concentrations diminuent très rapidement et se maintiennent sensiblement à la même valeur jusqu'au fond.

Les biomasses chlorophylliennes présentes dès la mise en eau en 1994 se sont surtout développées en 1995, puis ont légèrement décliné en 1996 (tableau 1). La bactériochlorophylle a présenté un maximum des concentrations en 1994, puis a régulièrement baissé jusqu'en 1996. II faut enfin remarquer la descente en profondeur des maximums des concentrations des deux pigments, de $2-3 \mathrm{~m}$ en 1994, à 3-5 m en 1995, et enfin à 5$10 \mathrm{~m}$ en 1996.

\subsection{Distribution spatiale amont - aval des pigments}

Les biomasses chlorophylliennes (mesurées en surface) se distribuent le long d'un transect longitudinal amontaval, entre Takari-Tanté et BPS1, suivant trois zones plus ou moins bien différenciées (fig. 5) : la zone amont,

Tableau 1. - Moyennes, écart-types et intervalles de variations des concentrations $\left(\mu \mathrm{g} \mathrm{I}^{-1}\right)$ en chlorophylle $a$ et bactériochlorophylle à la station BPS1, dans la couche $0-10 \mathrm{~m}$.

Table 1. - Annual means, standard deviations and ranges of the chlorophyll $a$ and bacteriochlorophyll concentrations $\left(\mu \mathrm{gl}^{-1}\right)$ in the $0-10 \mathrm{~m}$ upper layer at station BPS1.

\begin{tabular}{|c|c|c|c|c|}
\hline & & 1994 & 1995 & 1996 \\
\hline \multirow[b]{2}{*}{ Chl a } & Moyenne & 4,7 & 12,7 & 10,4 \\
\hline & Ecartype & 4,2 & 11,7 & 7,4 \\
\hline \multicolumn{2}{|r|}{ Min - Max } & $0,1-20$ & $1-74,4$ & $1,4-78,9$ \\
\hline \multirow{3}{*}{ Bchl } & Moyenne & 61,9 & 45,3 & 15,7 \\
\hline & Ecartype & 57,9 & 48,2 & 26,2 \\
\hline & Min - Max & $1,1-317,4$ & 3- 238,1 & $0,1-124,6$ \\
\hline \multicolumn{2}{|c|}{ Nombre de mesures } & 97 & 269 & 265 \\
\hline
\end{tabular}




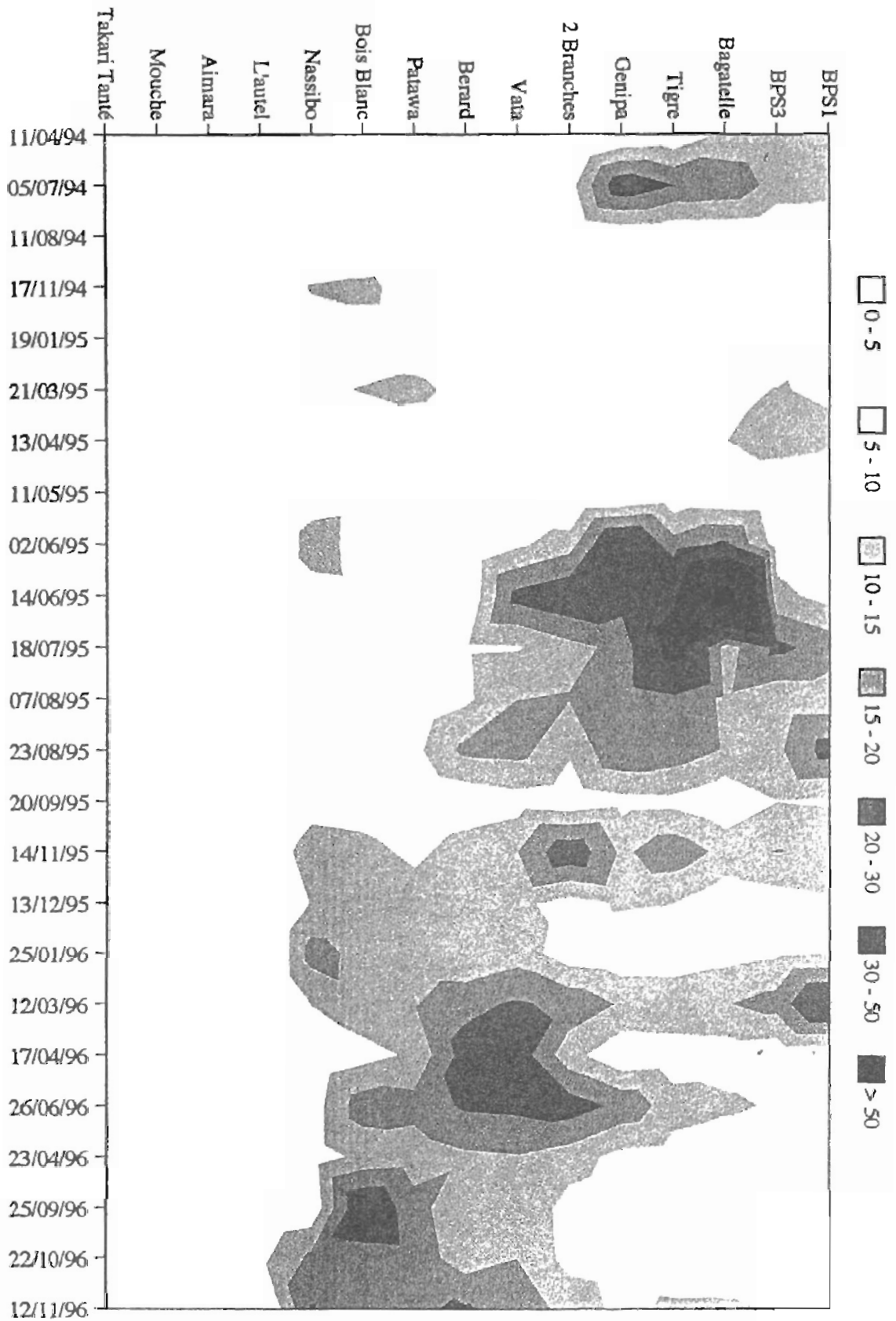

Fig. 5. - Evolution des concentrations de chlorophylle a $\left(\mu \mathrm{gl}^{-1}\right)$ le long d'un transect amont (Takarì-Tanté) - aval (BPS1) à 0,30 m de profondeur dans le lac de Petit-Saut de 1994 à 1996.

Fig. 5. - Variations of chlorophyll a concentrations $\left(\mu \mathrm{g}^{-1}\right)$ in $0.3 \mathrm{~m}$ collected samples from TakariTanté to BPS1 during the ' $94-96$ period. 
de Takari Tanté à Aïmara où la biomasse phytoplanctonique est toujours inférieure à $0,2 \mu \mathrm{gl}^{-1}$, une zone intermédiaire entre Saut-l'Autel et BoisBlanc où se produit la mise en place du peuplement phytoplanctonique et enfin une zone s'étendant de Patawa jusqu'à Petit-Saut où les biomasses chlorophylliennes varient plus ou moins fortement suivant les stations et les périodes. Les maximums de biomasse se sont déplacés entre Saut-Vata et Petit-Saut en 1994 et 1995, puis entre Nassibo et Génipa en 1996. La chlorophylle a semble se répartir de façon uniforme et à des concentrations moins élevées dans la zone du barrage (BPS1 à Génipa) que dans les parties plus amont de la retenue, pour la couche de surface. La bactériochlorophylle est partout présente entre $3 \mathrm{~m}$ et $8 \mathrm{~m}$ de profondeur (maximums des concentrations suivant les périodes), au moins jusqu'à Saut-Patawa, alors qu'elle n'est pas détectée pour les stations les plus amont.

A l'aval du barrage, les concentrations en chlorophylle a sont en moyenne de $4,4 \mathrm{\mu g} \mathrm{I}^{-1}$. Relativement faibles en $1994\left(1,2 \mu \mathrm{gl}^{-1}\right)$, elles ont évolué à 5,0 et $4,4 \mathrm{Mgl}^{-1}$ en moyenne en 1995 et 1996. On constate distinctement une augmentation des teneurs dans le fleuve juste à l'amont du barrage durant la saison seche de 1995 et dans une moindre mesure de 1996. II en est de même pour la bactériochlorophylle, dont les teneurs ont été plus élevées durant ces trois années $\left(19,7 \mu \mathrm{gl}^{-1}\right.$, en moyenne), diminuant de 28,1 en 1994 à 19,9 en 1995 et
$18,1 \mathrm{~g} \mathrm{I}^{-1}$ en 1996. Les concentrations de chlorophylle a à l'aval sont significativement dépendantes des concentrations moyennes calculées sur toute la colonne d'eau à l'amont du barrage, tant au niveau du seuil qu'à Kerenroch $\left(r^{2}=0,63\right)$. Cette tendance n'est pas significative pour la bactériochlorophylle. La relation plus ou moins forte entre l'aval et l'amont dépend directement de la fraction de la colonne d'eau concernée par le turbinage et/ou les relargages. Les variations des concentrations au-delà du seuil sont dépendantes du mélange des eaux, des apports secondaires des criques (effet de dilution) et de la dynamique propre des peuplements de microorganismes. Les concentrations de chlorophylle $a$ et de bactériochlorophylle (fig. 6) diminuent du seuil jusqu'à l'embouchure, avec une baisse significative à Venus, sans doute sous l'effet des apports de Crique Venus (respectivement 0,2 à $0,5 \mu \mathrm{gl}^{-1}$ ) et à Sinnamary sous l'influence marine qui peut se répercuter jusqu'à Pointe-Combi. Cette diminution à partir du barrage jusqu'à Sinnamary indique qu'aucun développement des algues et des bactéries photosynthétiques ne se produit durant le parcours jusqu'à la mer.

\subsection{Variations inter et infra-journalières des pigments}

Les variations inter-journalières des concentrations de chlorophylle a peuvent être très importantes, au moins dans la couche de surface, dans un rapport de 1 à 2 ou 3 ; elles sont 


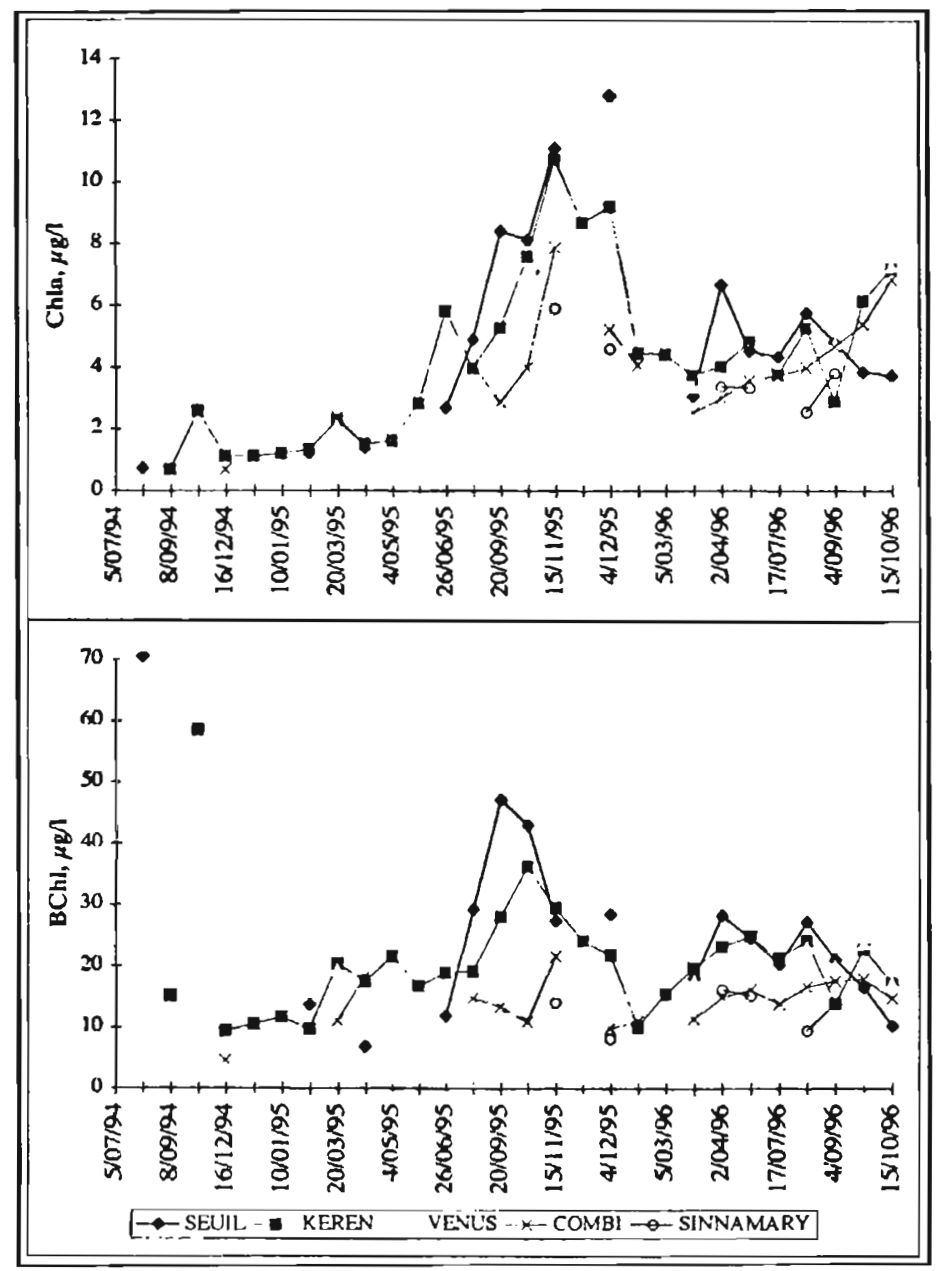

Fig. 6. - Evolution des concentrations de chlorophylle a $\left(\mu \mathrm{gl}^{-1}\right)$ et de bactériochlorophylle $\left(\mu \mathrm{g}^{-1}\right)$ en surface à 5 stations situées à l'aval du barrage dans le fleuve Sinnamary.

Fig. 6. - Variations of surface chlorophyll $a$ and bacteriochlorophyll concentrations at 5 stations located in the river Sinnamary downstream the dam.

beaucoup plus réduites dans la zone aphotique (fig. 7). Pour la bactériochlorophylle, les variations inter-journalières sont du même ordre de grandeur que les variations infra-journalières dans la zone où se produisent les maximums de développement des organismes (fig. 7). Des variations importantes, dans un rapport de 1 à 3-4, peuvent être notées sur les profils longitudinaux sur une période de 2 ou 3 jours (fig. 8). Elles peuvent concerner l'ensemble des 

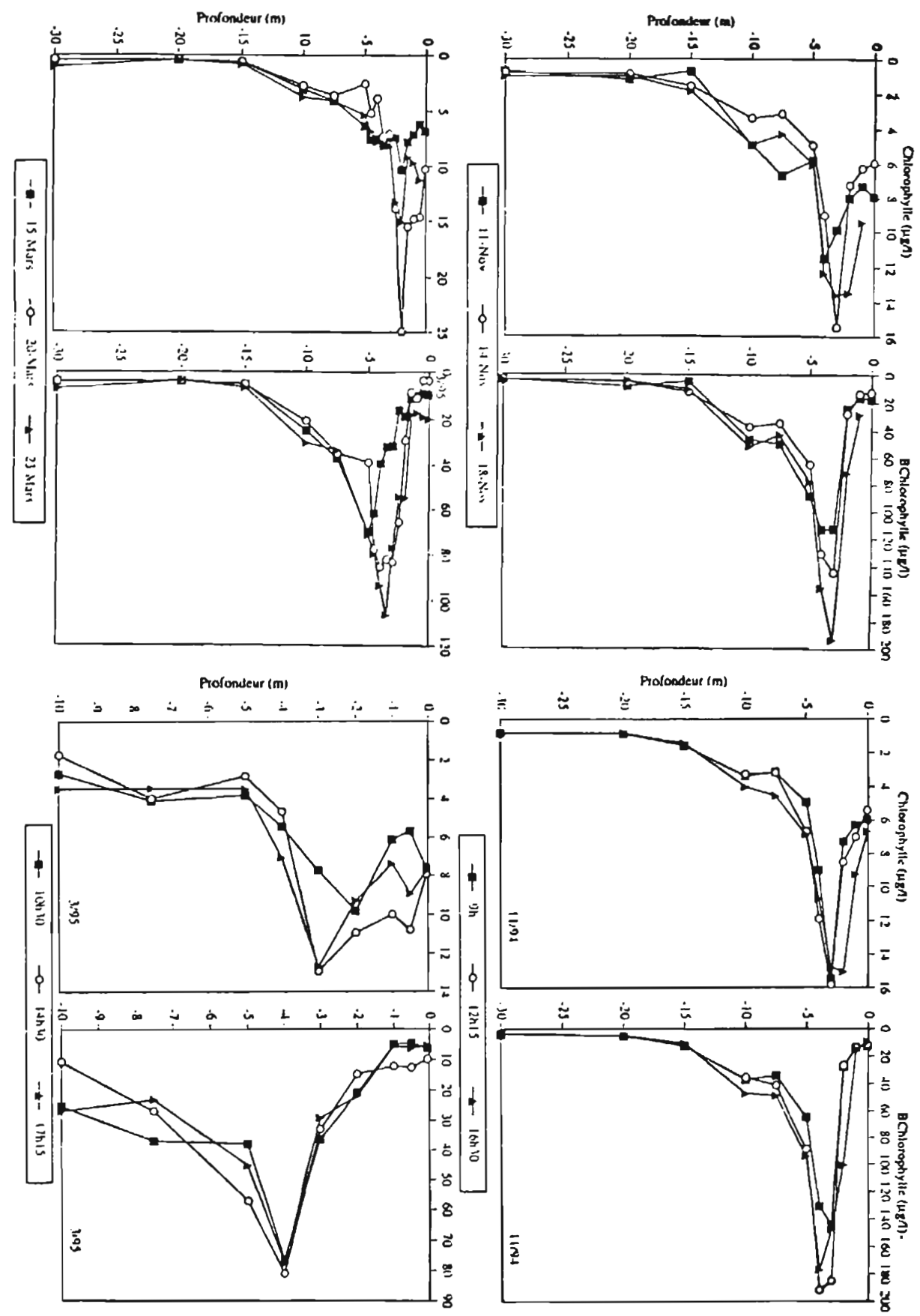

Fig. 7. - Variations interjournalieres et infrajournalieres de la distribution verticale de la chlorophylle a et de la bacteriochlorophylle a la station BPS1, en novembre 1994 et mars 1995.

Fig. 7. - Day and hour scale variations of the vertical distribution of chlorophyll $a$ and bacteriochlorophyll at station BPS, in November 1994 and March 1995. 


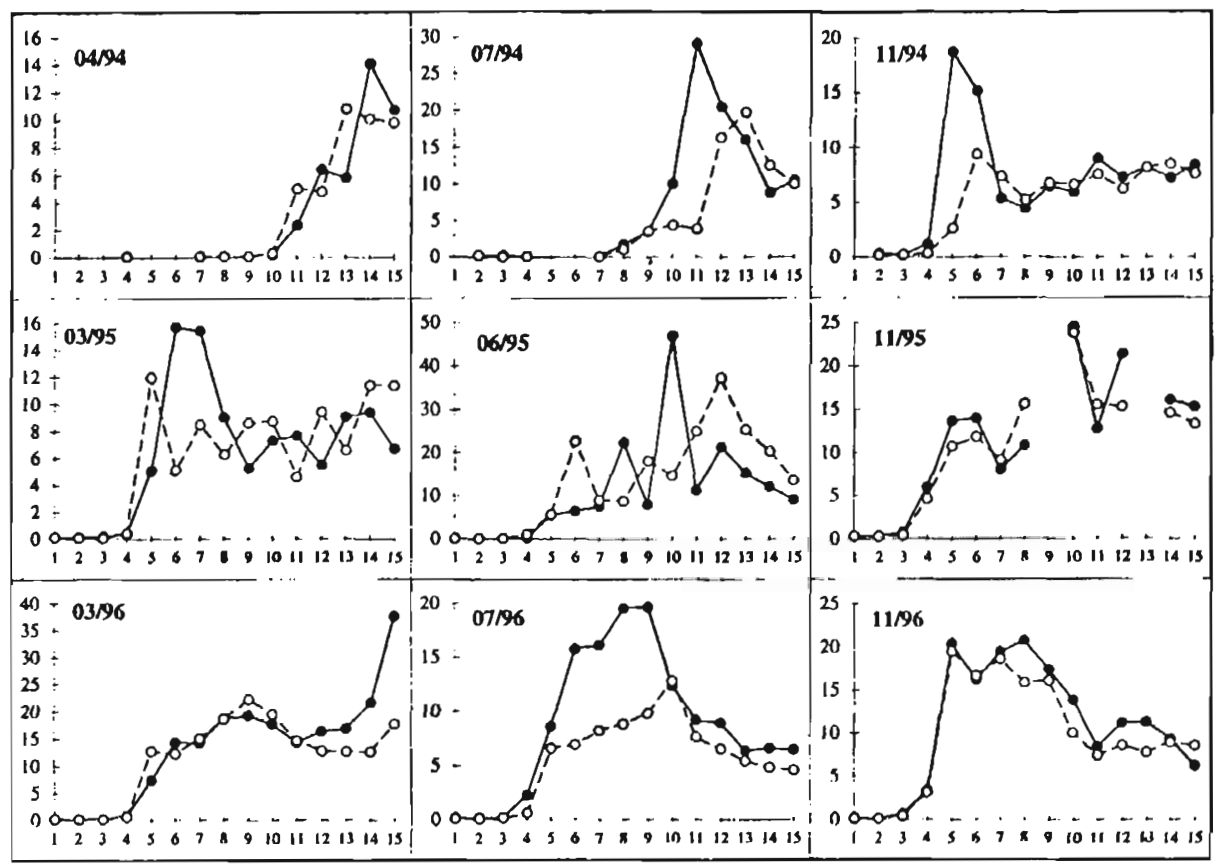

Fig. 8. - Variations des concentrations de chlorophylle a $\left(\mu \mathrm{gl}^{-1}\right)$ à $0,30 \mathrm{~m}$ de profondeur le long du transect longitudinal amont (Takari-Tanté, 1) - aval (BPS1, 15) dans le lac de Petit-Saut, du jour $j(\bullet)$ au jour j+1 ( $V$ ) a a cours de 9 campagnes de prélevements de 1994 à 1996.

Fig. 8. - Variations of chlorophyll a concentrations $\left(\mu \mathrm{gl}^{-1}\right)$ in $0.3 \mathrm{~m}$ samples collected along the Takari-Tanté - BPS1 transect, from day $d(\bullet)$ to day $d+1(v)$ during 9 sampling campaigns from 1994 to 1996.

stations $(03 / 95$; 06/96) ou bien seulement certaines zones $(07 / 94 ; 07 / 96)$.

Le déplacement de la profondeur des maximums des deux pigments reste inférieur ou au plus égal à $1 \mathrm{~m}$, aussi bien sur des périodes de plusieurs jours qu'au cours d'une même journée. Une part de ces variations est sans doute imputable à l'échantillonnage et traduirait à certaines périodes une hétérogénéité des masses d'eau, liée notamment à l'hydrodynamisme. Cependant les différences importantes sur plusieurs stations successives (07/94; 11/94; 03/95; 07/96) sont vraisemblablement plus liées à des activités biologiques, telles que la productivité propre du phytoplancton et le "grazing", d'autant plus vraisemblable que ces variations de biomasse se produisent dans les zones où s'installent et se dévelop- 
pent les peuplements zooplanctoniques.

\subsection{Productivité du phytoplancton}

Des mesures de production primaire effectuées à diverses reprises par la méthode de l'oxygène ont montré que le phytoplancton pouvait produire entre 0,1 et $0,3 \mathrm{mg} \mathrm{l}^{-1} \mathrm{~h}^{-1}$ d'oxygène, correspondant à une assimilation de 35 à $110 \mu \mathrm{gl}^{-1} \mathrm{~h}^{-1}$ de carbone, pour un rap- port optimal O2: $\mathrm{C}=2,67$. Ces mesures de production sont cohérentes avec l'évolution journalière des concentrations en $\mathrm{O} 2$ mesurées en continu in situ. Cependant ces valeurs doivent être considérées avec prudence: les variations d'oxygène dans les flacons de mesures sont souvent proches de la limite de mesure liée à l'instrumentation, notamment dans la partie inférieure de la zone photique. Par ailleurs les variations observees au bout

Tableau 2. - Assimilation du carbone et production d'oxygène mesurées sur des profils verticaux $0-3 \mathrm{~m}$ à la station BPS1. Comparaison avec la production d'oxygène déduite de l'assimilation de $\mathrm{C}$ suivant le rapport $\mathrm{O} 2$ / $\mathrm{C}=2,67$.

Table 2. - Carbon assimilation and oxygen production measured on $0-3 \mathrm{~m}$ vertical profiles at station BPS1. Comparison with oxygen production calculated from $\mathrm{C}$ assimilation by using $\mathrm{O} 2 / \mathrm{C}=2.67$.

\begin{tabular}{||c|c|c|cc||}
\hline & Assimilation & \multicolumn{2}{|c|}{ Production d'O2 } \\
& Profondeur $(\mathrm{m})$ & $\begin{array}{c}\text { As } \mathrm{C}(\mu \mathrm{g} / / \mathrm{h}) \\
(\mu \mathrm{g} / / \mathrm{h}) \text { calculée }\end{array}$ & $(\mu \mathrm{g} / / \mathrm{h})$ mesurée \\
\hline $16 / 07 / 96$ & 0 & 24,9 & 67,7 & $(-)$ \\
& $-0,5$ & 14 & 38,2 & 37,5 \\
& -1 & 11,8 & 32,1 & 56,3 \\
& $-1,5$ & 7,2 & 19,7 & 0 \\
& -2 & 5,3 & 14,3 & 37,5 \\
& -3 & 2,8 & 7,6 & $(-)$ \\
\hline $17 / 07 / 96$ & 0 & 24,1 & 65,7 & 74,1 \\
& $-0,5$ & 19,5 & 53 & 59,3 \\
& -1 & 20,4 & 55,5 & 44,4 \\
& $-1,5$ & 13,5 & 36,8 & 44,4 \\
& -2 & 7,3 & 19,8 & 29,6 \\
& -3 & 4,6 & 12,5 & 0 \\
\hline $18 / 07 / 96$ & 0 & 36,4 & 99 & 50,7 \\
& $-0,5$ & 31,3 & 85,2 & 135,1 \\
& -1 & 26 & 70,6 & 118,2 \\
& $-1,5$ & 19,9 & 54,2 & 50,7 \\
& -2 & 13 & 35,3 & 33,8 \\
\hline
\end{tabular}


de quelques heures d'incubation résultent d'un ensemble de processus biologiques et chimiques, où ces derniers peuvent avoir des incidences importantes, compte tenu de la présence de grandes quantités d'éléments réducteurs provenant de la zone anoxique, et qui peuvent être exacerbées par le confinement plus ou moins long dans les flacons d'incubation. La production primaire évaluée avec cette technique n'est quasiment pas mesurable en dessous de 2 à $3 \mathrm{~m}$ de profondeur, alors que la zone photique a atteint au moins $5 \mathrm{~m}$ en 1996. Quelques mesures directes d'incorporation de carbone montrent que cette méthode donne des valeurs de production du même ordre de grandeur que celles obtenues par la méthode de l'oxygène, mais pas toujours concordantes (tableau 2). Les valeurs d'assimilation de carbone rapportées à la quantité de chlorophylle présente dans le milieu sont relativement faibles, $<4 \mu \mathrm{gC} \mu \mathrm{g}$ $\left(\right.$ Chla) ${ }^{-1} \mathrm{~h}^{-1}$ (tableau 3). Ces valeurs sont vraisemblablement minimales dans la mesure où les quantités de carbone minéral disponible sont sousestimées du fait de la production d'une quantité importante de $\mathrm{CO}_{2}$ provenant de la dégradation de la matière organique dans les couches profondes. Inversement il est difficile d'évaluer l'utilisation de ce carbone minéral par les algues.

Comme la biomasse chlorophyllienne, la production primaire est donc limitée à la couche supérieure (0-5 m) de la colonne d'eau, correspondant à la couche photique. Les coefficients d'atténuation de la lumière ont diminué de 2,5 à $0,95 \mathrm{~m}^{-1}$ depuis la mise en eau, dans la zone lacustre, correspondant à une augmentation de la profondeur du point de compensation de la photosynthèse $(1 \%$ de transmission de la lumière mesurée juste sous

Tableau 3. - Production primaire par unité de volume et de biomasse chlorophyllienne sur des profils $0-5 \mathrm{~m}$ aux stations BPS1 et Genipa en novembre 1996.

Table 3. - Primary production referred water volume and chlorophyll biomass on 0 $5 \mathrm{~m}$ vertical profiles at stations BPS1 and Genipa in November 1996.

\begin{tabular}{|c|c|c|c|c|}
\hline \multirow[b]{2}{*}{ Profondcurs (m) } & \multicolumn{2}{|c|}{ BPS 1-6/11/96 } & \multicolumn{2}{|c|}{ GENIPA-7/11/96 } \\
\hline & $\mu \mathrm{gC} / \mathrm{l} / \mathrm{h}$ & $\mu \mathrm{gC} / \mu \mathrm{g}$ Chla $/ \mathrm{h}$ & $\mu \mathrm{gC} / 1 / \mathrm{h}$ & $\mu \mathrm{gC} / \mu \mathrm{g} \mathrm{Chla/h}$ \\
\hline$-0,01$ & 24,8 & 2,57 & 19,9 & 1,63 \\
\hline$-0,5$ & 34,5 & $\overline{3}, \overline{4} 8$ & 32,7 & 2,7 \\
\hline-1 & 24,2 & 2,35 & 31,8 & 2,67 \\
\hline$-1,5$ & 18,1 & 1,75 & 25,1 & 2,09 \\
\hline-2 & 11,2 & 1,08 & 21 & 1,74 \\
\hline-3 & 5,8 & 0,54 & 9,5 & 0,78 \\
\hline-4 & $2, \overline{8}$ & 0,25 & 4 & 0,34 \\
\hline-5 & 1,9 & 0,16 & 1.7 & 0,14 \\
\hline
\end{tabular}




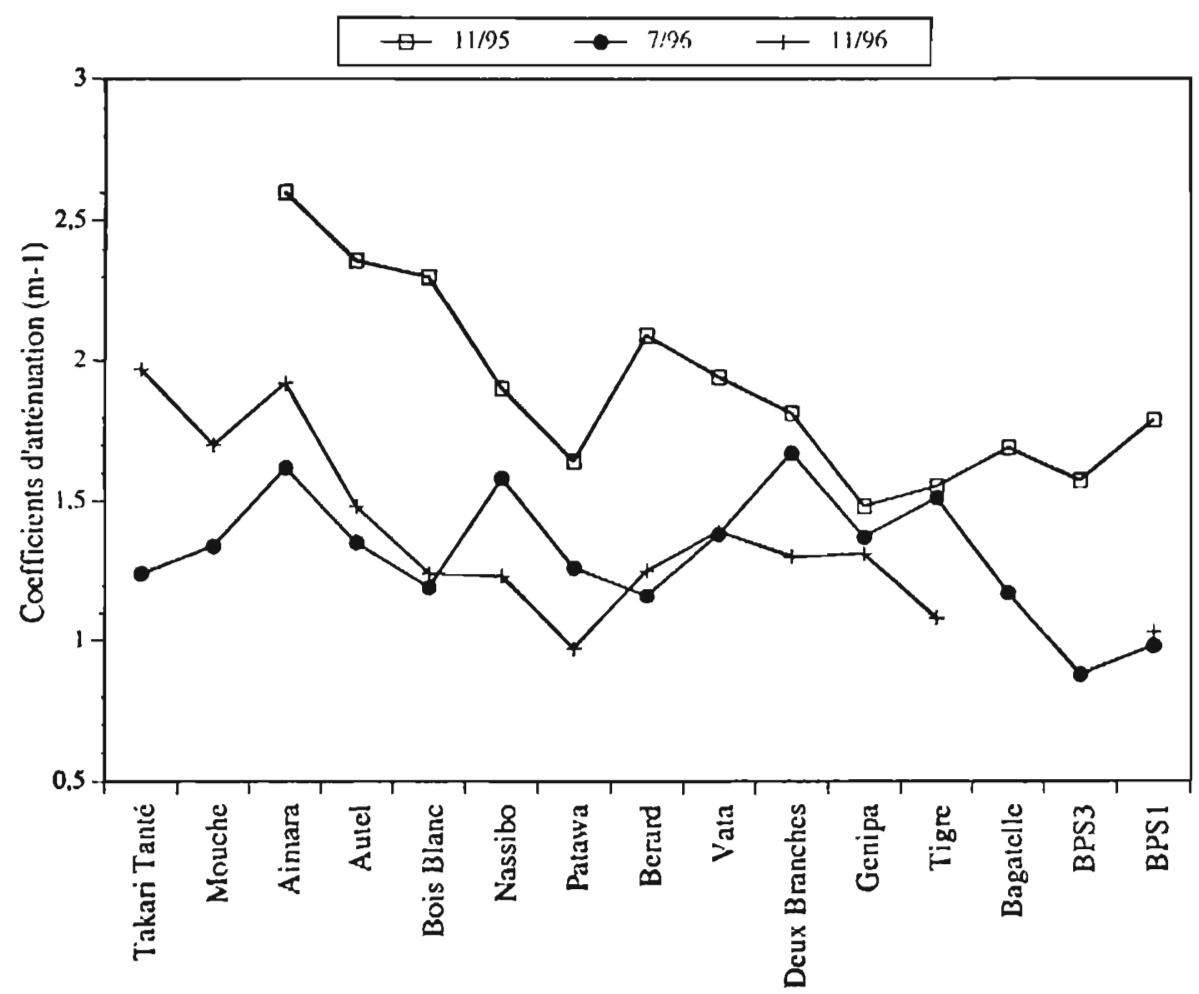

Fig. 9. - Evolution des coefficients d'atténuation de la lumière dans l'eau entre Takari-Tanté et BPS1.

Fig. 9. - Evolution of light attenuation coefficients in water from Takari-Tanté to BPS1.

la surface de l'eau), entre 1,8 et $5 \mathrm{~m}$ environ. Le long des profils longitudinaux (fig. 9), les coefficients d'atténuation sont les plus élevés entre Bois-Blanc et Takari-Tanté $\left(>2 \mathrm{~m}^{-1}\right)$, zone soumise à l'influence des apports d'eau chargée en matières particulaires du fleuve Sinnamary et maintenues plus ou moins longtemps en suspension sous l'effet du courant. Les valeurs sont ensuite plus faibles entre Bois-Blanc et le barrage, par suite de la sédimentation des ma- tières en suspension, mais variant en fonction de la charge résiduelle et celle liée à l'activité biologique.

Les concentrations de $\mathrm{N}-\mathrm{NH} 4$ sont de l'ordre de 20 à 60 mole $^{-1}$ dans la couche photique, tandis que celles de P-PO4 sont voisines de 0,2 à $0,5 \mu^{m o l e} l^{-1}$ et celles du phosphore total proches de $1 \mu^{\text {mole }}{ }^{-1}$ (Richard, 1996). Les rapport N/P supérieurs à 30 indiquent que la production serait contrôlée par la disponibilité en phosphore. Mais les concentrations dans 
la couche inférieure sont très largement supérieures à 100 et $1 \mu$ mole l$^{-1}$ pour ces deux éléments, et représentent des stocks permettant des flux importants de nutriments vers la surface. Les nutriments ne semblent donc pas devoir limiter actuellement le phytoplancton. Toutefois cette disponibilité pourrait être restreinte du fait de la présence à l'interface des zones oxygénée et anoxique d'une flore de bactéries photosynthétiques apparemment très actives, démontrée par les concentrations élevées de bactériochlorophylle, qui pourraient être des compétiteurs pour l'assimilation de ces éléments.

\section{DISCUSSION}

Le réservoir de Petit-Saut a été colonisé par le phytoplancton dès sa mise en eau en 1994. La biomasse algale est relativement élevée dès cette période, comme cela est souvent observé lors de la création de réservoirs, en relation avec la mobilisation de quantités importantes d'éléments nutritifs présents dans les sols submergés. Ce développement algal est également favorisé par le passage d'un système fluvial à écoulement plus ou moins rapide et turbulent à un système lacustre, calme. Les caractéristiques physico-chimiques (anoxie, concentration élevée en ion ammonium, abondance des composés réduits produits dans la zone anoxique) établies dès la mise en eau du réservoir (Richard, 1996) ont plutôt favorisé les espèces banales, cosmopolites et ubiquistes qui constituent la flore planctonique, souvent tolérantes à une large gamme de conditions environnementales et sans doute plus adaptées à la phase pionnière de coIonisation d'un milieu nouveau. Les espèces algales typiques des milieux acides tropicaux ont augmenté à partir de 1995, au niveau notamment du "biofouling" qui s'est développé sur les supports immergés. Mais la biodiversité est encore aujourd'hui relativement faible par rapport à celle mise en évidence dans les milieux côtiers guyanais. L'augmentation de ces espèces plus typiques pourrait être un indice de l'amélioration des conditions environnementales: augmentation des zones photique et oxique notamment.

L'origine du peuplement n'est pas mise en évidence de façon claire, notamment dans les apports par le fleuve Sinnamary où les algues sont très peu abondantes $\left(<10^{5}\right.$ cellules $\left.1^{-1}\right)$ et le plus souvent représentées dans le nanoplancton par des Diatomées de dérive. Mais la rareté des individus n'est cependant pas synonyme d'absence d'autant que plusieurs espèces observées dans la retenue ont été décrites dans diverses criques forestières de Guyane (Thérézien, 1985). La submersion de nombreuses criques lors de la montée des eaux a sans doute contribué à l'ensemencement du lac. Par ailleurs, de petites zones de forêt inondée, soit par le Sinnamary soit par de petites criques latérales, plus ou moins ouvertes et à écoulement ralenti, ont constitué des zones de développement phyto- 
planctonique initial, contribuant de façon plus significative à l'ensemencement du milieu.

Une caractéristique remarquable du peuplement phytoplanctonique de Petit Saut est la présence d'une forte proportion des cellules de petites dimensions $(<2-3 \mu \mathrm{m})$ qui constituent le picophytoplancton. A la limite ou en deçà de la limite de détection par microscopie optique, il a pu être mis en évidence par CMF. Passé inaperçu ou indétectable jusqu'il y a une quinzaine d'années, le picophytoplancton constitue dans la plupart des milieux aquatiques une fraction souvent importante des peuplements phytoplanctoniques aussi bien marins que dulçaquicoles (Stockner et al., 1986; Stockner, 1988). Dans la retenue de Petit Saut, les dénombrements effectués à diverses reprises montrent que ces organismes sont dominants dans la zone photique où ils constituent plus de $60 \%$ de l'abondance numérique totale du peuplement et parfois jusqu'à $80 \%$ environ. L'origine de ces algues est locale puisqu'elles ont été dénombrées jusqu'aux stations les plus amont de la retenue. Mais l'apport par voie aérienne est une autre potentialité de colonisation mise en évidence lors d'études de plans d'eau nouvellement créés (Williams et al., 1994). Ces auteurs ont montré que ces apports étaient surtout constitués de tres petites algues. Le picophytoplancton du réservoir de Petit-Saut est sans doute composé d'eucaryotes appartenant au groupe des Chlorophycées, compte tenu de la composition pigmentaire majeure (chlorophylles a et $b$ ) mise en évidence. Son identité ne pourra être établie qu'à l'aide d'observations plus fines, en particulier en microscopie électronique. La prise en compte de l'abondance numérique des différentes catégories de cellules par rapport à l'indice de biomasse (concentration en chlorophylle a) est primordiale dans la mesure où une même quantité de pigment peut correspondre à des abondances et des tailles cellulaires très différentes. De plus les quantités de chlorophylle a cellulaire peuvent varier dans de fortes proportions (Sosik et al., 1989) suivant les conditions environnementales.

Les biomasses de phytoplancton relativement élevées depuis la mise en eau sont caractéristiques d'un milieu eutrophe, où les concentrations en éléments nutritifs ne semblent pas limiter la croissance du phytoplancton. La minéralisation de l'énorme quantité de matière organique immergée dans la retenue constitue une source de nutriments considérable. Les algues se distribuent verticalement suivant une zonation liée à la zone photique, les maximums se situant dans les premiers mètres de la colonne d'eau et correspondant également à la couche d'eau oxygénée. Le phytoplancton participe donc à l'oxygénation de la couche superficielle du lac. Mais l'interférence de cette production d'oxygène avec la consommation chimique (composés réduits provenant de la couche anoxique) et biologique (respiration et dégradation de la matière organique) ne permet pas d'évaluer correctement la contribution de la photosynthèse à ce bilan d'oxy- 
gène, du moins avec les méthodes chimiques classiques.

L'évolution des biomasses phytoplanctoniques (juste à l'amont du barrage) met en évidence une périodicité saisonnière du développement des algues: les concentrations en chlorophylle a sont les plus élevées pendant la saison sèche. Les maximums se produisent plutôt vers les niveaux inférieurs de la zone photique, juste au-dessus d'autres organismes photosynthétiques, vraisemblablement des bactéries photosynthétiques anaérobies, situés à la limite supérieure de la zone anoxique. Ces organismes se répandent plus ou moins dans la zone photique, probablement sous l'effet de turbulences, ou ils se mélangent au phytoplancton. Leurs pigments très voisins des pigments végétaux interfèrent alors avec ceux des algues lors de l'évaluation de leurs concentrations. Pendant la saison humide, les concentrations pigmentaires sont moins élevées du fait de la diminution importante de l'énergie lumineuse incidente sous le couvert nuageux plus ou moins permanent. Par ailleurs les biomasses sont réparties de façon plus homogène, par suite du mélange des eaux de surface sous l'influence de l'apport des eaux pluviales plus fraîches. La lumière apparaît donc comme le facteur contrôlant le développement du phytoplancton, déterminant à la fois une zone photique de faible épaisseur, mais tendant à gagner en profondeur, et une périodicité saisonnière nettement marquée.

Dans l'axe longitudinal amont-aval, le phytoplancton se distribue suivant une zonation déjà décrite pour d'autres réservoirs (Kimmel et al., 1986). La zone la plus amont est sous l'influence directe du fleuve Sinnamary. La transparence de l'eau y est très limitée en raison des quantités des matières particulaires importantes maintenues en suspension par les courants, s'ajoutant à la coloration par les composés organiques dissous, et ne permet pas le développement des peuplements d'algues très pauvres des eaux fluviales. Dès que le système lacustre se met en place, les peuplements phytoplanctoniques se développent, en liaison avec l'éclaircissement de l'eau $\left(1<\mathrm{k}<2 \mathrm{~m}^{-1}\right)$ dont une part est attribuable à la sédimentation des matières particulaires les plus lourdes. Le développement préférentiel du picophytoplancton peut être expliqué par une productivité plus élevée de ces organismes, favorisée par leur petite taille (Joint, 1991; Tang, 1995).

Si on admet que la croissance du phytoplancton n'est pas actuellement limitée par les éléments nutritifs, mais essentiellement par la lumière, les fluctuations longitudinales des biomasses peuvent être attribuées à l'équilibre production des alguesconsommation par le zooplancton. La covariation longitudinale des peuplements phytoplanctoniques et zooplanctoniques (Horeau, 1996), montre l'existence d'interactions trophiques. La zone de transition est caractérisée par une augmentation des biomasses phytoplanctoniques suivie par la mise en place d'une microfaune plus ou moins abondante qui se maintient 
dans la zone lacustre jusqu'au barrage. Les biomasses algales sont alors régulées sous l'impact du "grazing". Cette distribution spatiale horizontale des abondances du phytoplancton et du zooplancton décrit un système prédateurs-proies basé sur la succession dans le temps d'un niveau trophique au niveau trophique supérieur (Matveev, 1995). L'analogie entre le modèle de distribution spatiale et le modèle de succession temporelle peut trouver une partie de son explication dans la circulation des masses d'eau. La régulation des peuplements phytoplanctoniques par le "grazing" n'est surement pas sous la seule influence du mesozooplancton, si on se réfère notamment à l'abondance du picophytoplancton. Ce dernier entraîne sans doute le développement d'une microfaune planctonique intermédiaire diversifiée, telle la microfaune des Rotifères (Pourriot, 1996; Pourriot et al., sous presse) ou celle de ciliés observés avec le phytoplancton, dont certains éléments sont plus adaptés à l'ingestion de ces petites particules, y compris les bactéries.

\section{REMERCIEMENTS}

Les auteurs expriment leurs remerciements à l'ensemble des personnels du laboratoire Environnement de Petit-Saut (HYDRECO) pour l'aide très efficace apportée à la réalisation de ce travail, financé par le CNEH EDF (Chambéry - France).

\section{RÉFÉRENCES BIBLIOGRAPHIQUES}

Bourrelly P. \& A. Couté. 1982. Quelques algues d'eau douce de la Guyane Française. Amazoniana, 7 : 221-292.

Guerlesquin M., Couté A. \& A. Vaquer. 1991. Studies about the family of the Characeae from the Guyanas. Verh. Internat. Verein Limnol. 24 : 26732677.

Haripersad-Makhanal A. \& P.E. Ouboter. 1993. Limnology: physico-chemical parameters and phytoplankton composition, p. 53-75. In P.E. Ouboter (ed.) : Freshwater Ecosystems of Suriname. Kluwer Academic.

Horeau V. 1996. La mise en eau de la retenue hydroélectrique de Petit-Saut (Guyane). Hydrobiologie du fleuve Sinnamary avant la mise en eau, de la retenue pendant la mise en eau et du fleuve en aval. Thèse Doct. Univ. Marseille I, Centre Saint-Charles.

Jensen T.E. \& W.A. Corpe. 1994. Picoplanktonic cyanophytes from three small lakes with special reference to polyphosphate bodies. Algological Studies, $75:$ 149-156.

Joint 1. 1991. The allometric determination of pelagic production rates. J. Plankton Res., 13: 69-81.

Kimmel B.L., Lind O.T. \& L.J. Paulson. 1986. Reservoir primary production, p. 133-193. In Hall G.E. \& Van Den Avyle M.J. (eds.): Reservoir fisheries management: strategies for the 80's. Reservoir Committee, Am. Fish Soc.

Lechuga-Deveze C.H. 1994. Shift of acetone-extracted pigments due to unknown natural phytoplankton populations from Conception Bay, Gulf of California. Bulletin of Marine Science, $55:$ 248-255.

Matsumura-Tundisi T., Tundisi J.G., Saggoi A., Oliveira Neto A.L. \& E.G. Espindola. 1989. Limnology of Samuel Reservoir (Brazil, Rondonia) in the fil- 
ling phase. Verh. Internat. Verein Lim. nol, 1482-1488.

McMurter H.J.G. \& F.R. Pick. 1994. Fluorescence characteristics of a natural assemblage of freshwater picocyanobacteria. J. Freshwater Res., 16 : 911925.

Neveux J. \& F. Lantoine, 1993. Spectrofluorometric assay of chlorophylls and phaeopigments using the least squares approximation technique. Deep-Sea Research, 40 : 1747-1765.

Pourriot R. 1996. Rotifers from Petit-Saut reservoir (French Guyana), with the description of a new taxon. Hydrobiologia, 331: 43-52.

Pourriot R., Horeau V. \& C. Rougier. 1997. Filinia (Rotifera, Monogononta) populations in French Guyana: F. Novaezealandiae, $F$. saltator, with remarks on the variability of some characters. Archiv Hydrobiol (sous presse).

Richard S. 1996. La mise en eau de la retenue hydroélectrique de Petit-Saut (Guyane). Hydrochimie du fleuve Sinnamary avant la mise en eau, de la retenue pendant la mise en eau et du fleuve en aval. Thèse Doct. Univ. Marseille I, Centre Saint-Charles.

Riemman B. \& L.M. Jensen. 1991. Measurements of phytoplankton primary production by means of the acidification and bubbling method. J. Plankton Res., $13:$ 853-862.
Sosik H.M., Chisholm S.W. \& J. Olson. 1989. Chlorophyll fluorescence from single cells : interpretation of flow cytometric signals. Limnol. Oceanogr., 34: 1749-1761.

Steemann Nielsen E. 1952. The use of radioactive carbon $\left(\mathrm{C}^{14}\right)$ for measuring organic production in the sea. J. Cons. Int. Explor. Mer, 18: 117-140.

Stockner J.G. \& N.J. Antia, 1986. Algal picoplankton from marine and freshwater ecosystem: a multidisciplinary perspective. Can. J. Fish. Aquat. Sci., $43:$ 2472-2502.

Stockner J.G. 1988. Phototrophic picoplankton: an overview from marine and freshwater ecosystem. Limnol. Oceanogr., 33, 765-775.

Tang E.P.Y. 1995. The allometry of algal growth rates. J. Plankton Res., 17 : 1325-1335.

Thérézien Y. 1985. Contribution à l'étude des algues d'eau douce de la Guyane Française à l'exclusion des diatomées. Bibliothecca Phycologica (J. Cramer Publisher), 72, $275 \mathrm{p}$.

Troussellier, M., Courties C. \& A. Vaquer. 1993. Recent applications of flow cytometry in aquatic microbial ecology. Biol. Cell., 78 : 111-121.

Troussellier, M., Courties C. \& S. Zettelmaier. 1995. Flow cytometric analysis of coastal lagoon bacterioplankton and picophytoplankton: fixation and storage effects. Estuarine Coastal Shelf Sci., $40:$ 621-633. 